\title{
Associação do Disclosure Ambiental com o Valor de Mercado de Empresas Brasileiras
}

\author{
Bianca Cecon ${ }^{1}$, Nelson Hein ${ }^{2}$, Adriana Kroenke ${ }^{3}$ \\ ${ }^{1}$ Universidade Regional de Blumenau (FURB) - bcecon@outlook.com \\ ${ }^{2}$ Universidade Regional de Blumenau (FURB) - hein@furb.br \\ ${ }^{3}$ Universidade Regional de Blumenau (FURB) - akroenke@furb.br
}

\section{PALAVRAS-CHAVE}

Disclosure Ambiental.

Valor de Mercado.

Empresas Brasileiras.

Received 16.04.2018

Revised 14.08.2018

Accepted 19.09.2018

ISSN 1980-4431

Double blind review

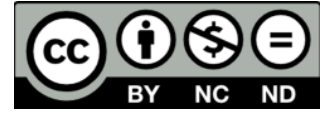

\section{RESUMO}

O estudo tem como objetivo avaliar a associação do disclosure ambiental com o valor de mercado de empresas brasileiras de alto impacto ambiental. Este tema tem evoluido particularmente no caso de empresas de mercados de capitais bem desenvolvidos (Santos et al., 2016). Contudo, essa não é a realidade das pesquisas com empresas de mercados de capitais emergentes, visto que este tema é pouco explorado (Uyar \& Kiliç, 2012). Como o Brasil é um dos principais países emergentes do mundo, destaca-se a importância desta pesquisa. Realizou-se uma pesquisa predominantemente quantitativa, com uma amostra de 24 empresas. O estudo procura contribuir em diversos aspectos com o tema proposto. Primeiro, procuramos mensurar o disclosure ambiental por meio da métrica de Rover (2013) utilizando a ponderação linear. Segundo, o valor de mercado das empresas foi calculado multiplicando o preço unitário das ações pela quantidade total de ações das organizações. Finalmente, para realizar a análise, foram determinados rankings utilizando a técnica de jogos escalares e de posse destes rankings, verificou-se a associação entre os mesmos por meio da análise de correlação de Kendall. Os achados do estudo indicam uma associação positiva do disclosure ambiental com o valor de mercado das empresas e, além disto, apresentaram um aumento no grau de associação do disclosure ambiental com o valor de mercado do ano de 2014 para o ano de 2015. Tal resultado sugere que o mercado está cada vez mais exigente quanto à divulgação de informações que envolvam o meio ambiente. Conclui-se que uma maior divulgação voluntária aumenta a vantagem competitiva da empresa.

\section{KEYWORDS}

Environmental disclosure. Market value. Brazilian companies.

\section{ABSTRACT}

The study aims to evaluate the association of environmental disclosure with the market value of Brazilian companies with high environmental impact. This issue has evolved particularly in the case of well-developed capital markets companies (Santos et al., 2016). However, this is not the reality of research with emerging capital markets companies, since this topic is little explored (Uyar \& Kiliç, 2012). As Brazil is one of the main emerging countries of the world, the importance of this research stands out. A predominantly quantitative research was carried out, with a sample of 24 companies. The study seeks to contribute in several aspects to the proposed theme. First, we seek to measure environmental disclosure using the Rover metric (2013) using linear weighting. Second, the companies' market value was calculated by multiplying the unit price of the shares by the total number of shares of the organizations. Finally, to perform the analysis, rankings were determined using the technique of scalar games and of possession of these rankings, the association between them was verified through the correlation analysis of Kendall. The findings of the study indicate a positive association of environmental disclosure with the market value of companies and, in addition, presented an increase in the degree of association of environmental disclosure with market value in the period from 2014 to the year 2015. Such a result suggests that the market is increasingly demanding about the dissemination of information that involves the environment. It is concluded that greater voluntary disclosure increases the competitive advantage of the company. 


\section{Introdução}

No período posterior à segunda metade do século XX, os usuários das informações contábeis passaram a exigir das organizações informações diferentes das tradicionalmente apresentadas. Este fato, de acordo com Oliveira et al. (2004), pode ser considerado uma das principais razões do tema disclosure ter ganhado destaque na área de Ciências Contábeis.

O termo disclosure refere-se ao ato de tornar algo público, ou seja, divulgar, disseminar, expor ou revelar algo, sendo que no contexto organizacional, o mesmo refere-se especificamente a divulgação de informações sobre a empresa (Murcia et al., 2010). Conforme mencionado por Lins e Silva (2009), utiliza-se o termo disclosure na contabilidade, como sendo sinônimo de divulgação, abertura ou evidenciação de informações qualitativas e quantitativas.

$\mathrm{O}$ disclosure nas organizações pode ocorrer tanto de forma compulsória, quanto de forma voluntária. A forma compulsória do disclosure ocorre por consequência de uma regulação, no qual a empresa é obrigada a divulgar determinada informação devido uma lei ou norma. Por outro lado, o disclosure realizado de forma voluntária, geralmente ocorre por meio de incentivos recebidos pelos administradores para divulgar determinada informação, não havendo uma obrigação legal para se realizar tal evidenciação (Salotti \& Yamamoto, 2005).

Referente ao disclosure realizado de forma voluntária, destaca-se no contexto brasileiro a evidenciação de informações de caráter ambiental. Contudo, destaca-se as incisivas recomendações da Agência Nacional de Energia Elétrica (ANEEL) para que empresas do setor de energia elétrica divulguem certas informações de caráter ambiental (Rover, 2013).

Em relação à evidenciação voluntária pelas organizações, Dye (2001) afirma existir a Teoria do Disclosure Voluntário, a qual possui como premissa central que a organização somente irá divulgar informações que são favoráveis para elas e não divulgarão informações desfavoráveis. Logo, se as empresas não divulgarem alguma informação, o mercado consequentemente irá interpretá-la como sendo negativa, pois se a mesma fosse positiva, não teria o porquê as organizações esconderem tal informação do mercado (Dye, 1985; Salotti \& Yamamoto, 2005). Verrecchia
(1983) salienta ainda em seu trabalho que os usuários podem até pensar que as informações não evidenciadas são positivas, porém pensarão ao mesmo tempo que por não terem sido evidenciadas, as mesmas não são suficientemente positivas para compensar os custos.

Logo, frente a este cenário, no qual os usuários externos a organização vem cobrando cada vez mais transparência das empresas em relação às questões ambientais realizadas pelas mesmas (Sobhani et al., 2009), a não divulgação destas informações pode prejudicar a imagem da organização. Isto ocorre, pois se a empresa esconder certas informações o mercado pode-se presumir que o valor da mesma está sendo superestimado, o que levaria os investidores a se desfazerem de suas ações, e consequentemente levaria estas organizações a um valor de mercado inferior frente as suas concorrentes que evidenciam (Dye, 1985).

Frente a conclusão de Dye (1985) em relação a Teoria do Disclosure Voluntário e aos achados não conclusivos dos estudos anteriores que verificaram a associação entre a divulgação voluntária ambiental e o valor de mercado de empresas (Iatridis, 2013; Olayinka \& Oluwamayowa, 2014; Qiu et al., 2014; Sousa et al., 2014; Fazzini \& Dal Maso, 2016; Santos et al.,2016; Verbeeten et al., 2016), apresenta-se o objetivo desta pesquisa que consiste em avaliar a associação do disclosure ambiental com o valor de mercado de empresas brasileiras.

Para atender o objetivo faz-se necessário mensurar o disclosure ambiental para tornar a avaliação possível. Essa mensuração é realizada por meio da métrica de Rover (2013) utilizando-se ponderação linear. De posse destes dados, as empresas foram ranqueadas mediante jogos escalares com base no disclosure ambiental e este desempenho foi comparado com o valor de mercado das mesmas mediante correlação de Kendall.

Nascimento et al. (2009) enfatizam que, frente as atuais demandas referentes as preocupações ambientais das organizações, observa-se um aumento na quantidade de estudos envolvendo questões relacionadas ao disclosure ambiental das empresas. Porém, de acordo com Bauer e Naime (2012), os estudos referentes a tal questão ainda permanecem escassos no cenário brasileiro, o que incentiva a realização de novas pesquisas para o melhor entendimento sobre a

Revista de Negócios, v. 23, n. 2, p. 23-37, April, 2018. 
temática e o preenchimento desta lacuna de pesquisa.

Além disto, Santos et al. (2016) destaca que a relevância de realizar uma pesquisa envolvendo tal associação ocorre devido ao tema estar diretamente ligado com o paradigma do gestor em divulgar informações para os stakeholders. Sendo que, segundo Rover e Santos (2014), investigar esta questão pode vir a contribuir para as empresas, uma vez que essas podem aprimorar suas questões referentes ao disclosure frente aos achados de tal associação.

Logo, verifica-se que investigar a associação entre a divulgação ambiental e a sua relevância para o mercado de capitais é importante tanto em âmbito acadêmico como para os usuários das informações (Rover, 2013). Isso pode ser observado diante dos resultados desta pesquisa que mostram que o mercado aumenta suas exigências de divulgação referente a questões que envolvam o meio ambiente e assim, empresas de alto impacto ambiental tendem a apresentar melhor valor de mercado.

Em suma, estes resultados contribuem com as empresas que podem, mediante esta pesquisa, avaliar os aspectos de evidenciação ambiental voluntária e adequar os mesmos diante de empresas parceiras e/ou concorrentes. Para os usuários externos a importância destes resultados está na possibilidade de avaliar a empresa na qual pretende direcionar seus investimentos, considerando que empresas com maior índice de divulgação voluntária possuem maior vantagem competitiva.

\section{Referencial Teórico}

Neste capítulo expõem-se os aspectos teóricos que fundamentam a pesquisa. Para tanto, o presente capítulo está dividido em quatro momentos: Teoria do Disclosure Voluntário; Disclosure de Informações; Valor de Mercado; e Estudos Anteriores.

\subsection{Teoria do Disclosure Voluntário}

Em 2001 o periódico Journal of Accountingand Economics publicou vários estudos os quais buscaram apresentar os temas pesquisados na área contábil e possíveis sugestões de pesquisas futuras. Os autores Robert E. Verrecchia e Ronald A. Dye foram incumbidos em resumir e sugerir possibilidades de estudos futuros em relação ao tema Teoria do Disclosure (Salotti \& Yamamoto, 2005).

Segundo Verrecchia (2001) não há uma teoria abrangente e unificada sobre disclosure até o momento. Contudo o autor enfatiza a existência de três grandes categorias de pesquisa sobre disclosure, sendo as mesmas: Pesquisa sobre Divulgação Baseada em Eficiência, Pesquisa sobre Divulgação Baseada em Associação e Pesquisa sobre Divulgação Baseada em Julgamento. O Quadro 1 apresenta em síntese as principais características de cada uma destas categorias.

Quadro 1. Categorias de pesquisa sobre disclosure

\begin{tabular}{|c|c|}
\hline Categoria & Característica da Pesquisa \\
\hline $\begin{array}{l}\text { Pesquisa sobre } \\
\text { Divulgação } \\
\text { Baseada em } \\
\text { Eficiência } \\
\text { (efficiency-based } \\
\text { disclosure) }\end{array}$ & $\begin{array}{l}\text { As pesquisas referentes a } \\
\text { Divulgação Baseada em Eficiência } \\
\text { discutem quais os arranjos de } \\
\text { divulgação são preferidos na } \\
\text { ausência de conhecimento anterior } \\
\text { sobre a informação. Logo, artigos } \\
\text { deste tipo de pesquisa discutem } \\
\text { quais os tipos de divulgação mais } \\
\text { eficientes. }\end{array}$ \\
\hline $\begin{array}{c}\text { Pesquisa sobre } \\
\text { Divulgação } \\
\text { Baseada em } \\
\text { Associação } \\
\text { (association-based } \\
\text { disclosure) }\end{array}$ & $\begin{array}{l}\text { A principal preocupação das } \\
\text { pesquisas sobre Divulgação } \\
\text { Baseada em Associação é investigar } \\
\text { a relação ou associação da } \\
\text { divulgação de informações com as } \\
\text { mudanças ocorridas no } \\
\text { comportamento dos investidores. } \\
\text { Logo a característica diferenciada } \\
\text { deste tipo de pesquisa refere-se a } \\
\text { verificar os efeitos da divulgação em } \\
\text { variáveis como preços dos ativos e } \\
\text { volume de negociações. }\end{array}$ \\
\hline $\begin{array}{l}\text { Pesquisa sobre } \\
\text { Divulgação } \\
\text { Baseada em } \\
\text { Julgamento } \\
\text { (discretionary- } \\
\text { based disclosure) }\end{array}$ & $\begin{array}{l}\text { Os estudos sobre Divulgação } \\
\text { Baseada em Julgamento buscam } \\
\text { identificar quais os motivos que } \\
\text { levam a divulgação de informações. } \\
\text { Logo, busca-se por meio destas } \\
\text { verificar como os gestores e/ou } \\
\text { empresas decidem divulgar } \\
\text { determinadas informações. }\end{array}$ \\
\hline
\end{tabular}

Fonte: Adaptado de Verrecchia (2001).

Conforme Verrecchia (2001), uma teoria verdadeiramente abrangente referente o disclosure necessita reunir as três categorias de pesquisa apresentadas no Quadro 1. O autor menciona tal fato, pois conforme o mesmo uma teoria abrangente sobre disclosure necessita reconhecer adequadamente $o$ papel da eficiência, dos incentivos e a endogeneidade do processo de divulgação.

Por outro lado, Dye (2001) sob sua perspectiva não corrobora em partes com a visão de

Revista de Negócios, v. 23, n. 2, p. 23-37, April, 2018. 
Verrecchia (2001), visto que para o autor o que não existe é uma Teoria de Disclosure Obrigatório, por a mesma não ter amadurecido o suficiente até o momento para ser titulada como teoria. Contudo, para Dye (2001) existe a Teoria do Disclosure Voluntário, a qual possui como premissa central que "[...] qualquer entidade que esteja cogitando fazer uma divulgação irá divulgar somente informações favoráveis à entidade, e não divulgará informações desfavoráveis à mesma" (Dye, 2001, p. 184).

Frente à premissa central da Teoria do Disclosure Voluntário enfatiza-se que a não divulgação de informações por parte das empresas pode vir a ser interpretada como sendo algo negativo pelo mercado, uma vez que se a mesma fosse positiva não existiria motivos da organização escondê-la (Dye, 1985). Logo, para Dye (1985) a evidenciação de informações voluntariamente possui associação com o valor de mercado das empresas, visto que se a organização não divulgar determinada informação, o mercado pode presumir que seu valor está sendo superestimado, o que pode acarretar a venda das ações por parte dos investidores, implicando em um valor de mercado inferior para esta empresa frente as suas concorrentes que divulgam tais informações.

\subsection{Disclosure de Informações}

No meio contábil o disclosure de informações pode ser interpretado como sendo sinônimo de divulgação, abertura ou evidenciação de informações (Lins \& Silva, 2009). Para Murcia (2009), o mesmo pode ser entendido como sendo um canal transmissor de informações, responsável por levar a informação da empresa para o mercado. Tais informações transmitidas podem possuir formato qualitativo (expressa em palavras) ou quantitativo (expressa em número) (Gibbins et al., 1990).

Para Levitt (1998) o disclosure de informações possui grande relevância, visto que para o mercado de capitais alcançar sucesso, o seu uso por parte das empresas é inevitável, uma vez que o mesmo fornece confiança aos usuários externos para investirem nas organizações. Weil (2002) enfatiza ainda que o disclosure de informações auxilia o mercado de capitais a obter sucesso pelo fato do disclosure tornar a avaliação dos investidores mais precisa.

$\mathrm{O}$ disclosure de informações engloba dois formatos distintos de informação, visto que pode ocorrer de forma obrigatória ou voluntária pelas empresas (Cruz \& Lima, 2010; Zanoello et al., 2015). O Quadro 2 compara ambos os formatos de informação.

Quadro 2. Comparação entre o disclosure compulsório e o disclosure voluntário

\begin{tabular}{|c|c|c|}
\hline $\begin{array}{r}\text { Forma de } \\
\text { Divulgação }\end{array}$ & $\begin{array}{l}\text { Disclosure } \\
\text { Obrigatório }\end{array}$ & $\begin{array}{l}\text { Disclosure } \\
\text { Voluntário }\end{array}$ \\
\hline Definição & $\begin{array}{lr}\text { Informação } & \text { que } \\
\text { deve ser divulgada } & \\
\text { de acordo com a lei } \\
\text { de } & \text { valores } \\
\text { mobiliários, } & \text { os } \\
\text { princípios } & \text { de } \\
\text { contabilidade } & \text { e } \\
\text { normas } & \text { das } \\
\text { agências } & \\
\text { reguladoras. } & \end{array}$ & $\begin{array}{l}\text { Exceto divulgação } \\
\text { obrigatória. } \\
\text { Informações } \\
\text { divulgadas pelas } \\
\text { companhias abertas } \\
\text { por uma questão de } \\
\text { imagem } \\
\text { corporativa, } \\
\text { relacionamento } \\
\text { com investidores, } \\
\text { assim como evitar a } \\
\text { acusação de riscos. }\end{array}$ \\
\hline Motivo & \begin{tabular}{|lr} 
Utiliza as leis e \\
regulamentos & para \\
ajustar & a \\
comunicação & de \\
informação entre as \\
empresas cotadas e \\
demais r partes \\
interessadas.
\end{tabular} & $\begin{array}{l}\text { Comunicação de } \\
\text { informação de auto } \\
\text { interesse entre as } \\
\text { empresas cotadas e } \\
\text { outras partes } \\
\text { interessadas. }\end{array}$ \\
\hline Conteúdo & $\begin{array}{l}\text { Apresentação das } \\
\text { empresas, } \\
\text { informações } \\
\text { financeiras básicas, } \\
\text { informações sobre o } \\
\text { conselho e a alta } \\
\text { gerência, } \\
\text { transações } \\
\text { importantes e } \\
\text { explicação para } \\
\text { itens importantes. }\end{array}$ & $\begin{array}{l}\text { Estratégias futuras } \\
\text { da empresa, planos } \\
\text { de pesquisa e } \\
\text { desenvolvimento, } \\
\text { informações de } \\
\text { previsão, compra e } \\
\text { fusão, análise de } \\
\text { projetos } \\
\text { investimento de } \\
\text { análise } \\
\text { informações } \\
\text { financeiras, etc. }\end{array}$ \\
\hline Transmissor & \begin{tabular}{|lr} 
Relatório & anual, \\
relatórios & \\
intercalares & $\mathrm{e}$ \\
relatórios & $\mathrm{de}$ \\
temporada. & \\
\end{tabular} & $\begin{array}{l}\text { Relatórios anuais, } \\
\text { anúncio público, } \\
\text { folhetos, rite, } \\
\text { roadshow, etc. }\end{array}$ \\
\hline Tempo & $\begin{array}{l}\text { Tempo fixo em um } \\
\text { ano e uma } \\
\text { temporada. }\end{array}$ & No tempo certo. \\
\hline $\begin{array}{l}\text { Mecanismo de } \\
\text { equilíbrio }\end{array}$ & $\begin{array}{l}\text { Leis e normas de } \\
\text { execução. }\end{array}$ & $\begin{array}{lr}\text { Concepção } & \text { dos } \\
\text { mecanismos } & \text { de } \\
\text { governança } & \\
\text { corporativa } & \text { e } \\
\text { eficácia. } & \\
\end{array}$ \\
\hline Origem da & Monopólio & Globalização \\
\hline
\end{tabular}




\begin{tabular}{|l|lr|lr|}
\hline divulgação & empresas & com & $\begin{array}{lr}\text { econômica } \\
\text { informações } \\
\text { globalização }\end{array}$ & do \\
próprias. & & mercado & de \\
capitais. & \\
\hline
\end{tabular}

Fonte: Tian e Chen (2009).

Verifica-se por meio do Quadro 2 que o disclosure obrigatório e o voluntário apresentam características distintas, contudo Tian e Chen (2009) enfatizam que ambos os formatos de disclosure são de grande relevância para a comunicação entre a empresa e seus usuários. Adina e Ion (2008) destacam ainda que mesmo o disclosure obrigatório e o voluntário possuindo finalidades distintas, ambos auxiliam de forma significativa na redução dos problemas de assimetria e no processo de tomada de decisão.

Adina e Ion (2008) salientam que a divulgação de informações de caráter voluntário passou a ganhar destaque devido às crises ocorridas nos Estados Unidos em 1929. Conforme Tian e Chen (2009) após estas crises os usuários começaram a pressionar as organizações a divulgarem informações além das evidenciadas devido alguma regulamentação. No cenário brasileiro informações referentes ao meio ambiental podem ser consideradas como voluntárias, visto que nas empresas; com exceção das de energia elétrica; não existem leis que obriguem as mesmas a divulgarem informações ambientais (Rover, 2013; Lopes et al., 2015).

\subsection{Valor de Mercado}

No meio contábil, econômico e legal a palavra valor assumi amplo sentido e por este motivo Neiva (1999) enfatiza a necessidade de utilizar termos para facilitar o significado da mesma, tais como: valor de mercado, valor atual, valor real, valor de liquidação, valor de livro, entre outros.

O valor de mercado de uma companhia diz respeito ao valor que o investidor está disposto a pagar pela mesma (Chaves \& Pimenta Junior, 2013). Esta disposição do investidor, de acordo com Santos et al. (2016) ocorre frente as expectativas geradas pelas empresas através das informações transmitidas para o mercado.

Logo, pelo fato do valor de mercado de uma organização refletir as expectativas dos investidores, tal valor diz respeito ao valor negociado das ações (Chaves \& Pimenta Junior,
2013). Na literatura que investiga a associação do disclosure ambiental com o valor de mercado das empresas evidenciaram-se três principais variáveis para mensurar o valor de mercado, sendo elas: Preço das Ações, Q de Tobin e Market-to-book.

Segundo Morais (2014) a variável mais adequada para explorar o valor de mercado das empresas quando analisada sua associação com o disclosure ambiental é o preço das ações. Fernandes et al. (2007), Pardo e Torro (2007), Furata e Santos (2010), Lian et al. (2011), Abrahamson e Ridder (2015) e Freguete et al. (2015) salientam que para calcular a mesma se faz necessário multiplicar o valor unitário de cada ação pela quantidade de ações da empresa.

\subsection{Estudos Anteriores}

Neste tópico tem-se por objetivo evidenciar os estudos anteriores localizados na literatura que investigaram a associação entre do disclosure ambiental com o valor de mercado de organizações. Cabe destacar que para localizar os mesmos foram realizadas buscas com as expressões "Disclosure socioambiental", "Disclosure ambiental", "Evidenciação socioambiental", "Evidenciação ambiental", "Divulgação socioambiental", "Divulgação ambiental" e "Environmental disclosure" nas seguintes bases: SciELO, Scopus, SPELL, Web of Science e no Portal de Periódicos da CAPES. O Quadro 3 apresenta os estudos localizados.

Quadro 3. Estudos anteriores sobre a temática

\begin{tabular}{|c|c|c|c|c|}
\hline Estudo & $\begin{array}{c}\text { Amostra e } \\
\text { Local do } \\
\text { Estudo }\end{array}$ & $\begin{array}{c}\text { Perío } \\
\text { do de } \\
\text { anális } \\
\text { e } \\
\end{array}$ & $\begin{array}{c}\text { Método } \\
\text { Utilizado }\end{array}$ & $\begin{array}{c}\text { Disclosure } \\
\text { Ambiental } \\
\text { e Valor de } \\
\text { Mercado }\end{array}$ \\
\hline $\begin{array}{l}\text { Iatridis } \\
(2013)\end{array}$ & $\begin{array}{c}529 \\
\text { empresas } \\
\text { cotadas na } \\
\text { Malásia. } \\
\end{array}$ & $\begin{array}{c}2005 \mathrm{a} \\
2011\end{array}$ & $\begin{array}{c}\text { Regressão } \\
\text { de dados } \\
\text { em painel }\end{array}$ & Positiva* \\
\hline $\begin{array}{c}\text { Olayinka e } \\
\text { Oluwamay } \\
\text { owa } \\
(2014) \\
\end{array}$ & $\begin{array}{c}50 \\
\text { empresas } \\
\text { cotadas na } \\
\text { Nigéria. } \\
\end{array}$ & $\begin{array}{c}2003 \mathrm{a} \\
2011\end{array}$ & $\begin{array}{c}\text { Regressão } \\
\text { de } \\
\text { dados em } \\
\text { painel } \\
\end{array}$ & Positiva* \\
\hline \multirow[b]{2}{*}{$\begin{array}{l}\text { Qiuet al. } \\
\text { (2014) }\end{array}$} & \multirow{2}{*}{$\begin{array}{c}11 \\
\text { empresas } \\
\text { em } 2005, \\
87 \mathrm{em} \\
2006,165 \\
\text { em } 2007, \\
214 \text { em } \\
2008 \text { e } 152 \\
\text { em } 2009\end{array}$} & \multirow[b]{2}{*}{$\begin{array}{c}2005 \mathrm{a} \\
2009\end{array}$} & $\begin{array}{c}\text { Correlaçã } \\
\text { o }\end{array}$ & $\begin{array}{c}\text { (Positiva } \\
\text { fraca) }\end{array}$ \\
\hline & & & Regressão & Positiva \\
\hline
\end{tabular}




\begin{tabular}{|c|c|c|c|c|}
\hline & $\begin{array}{l}\text { pertencente } \\
\text { s ao Índice } \\
\text { FTSE } 350 .\end{array}$ & & & \\
\hline \multirow[b]{2}{*}{$\begin{array}{l}\text { Sousa et } \\
\text { al. }(2014)\end{array}$} & \multirow{2}{*}{$\begin{array}{c}97 \\
\text { empresas } \\
\text { brasileiras } \\
\text { listadas } \\
\text { entre as } \\
\text { Maiores e } \\
\text { Melhores } \\
\text { da Revista } \\
\text { Exame, do } \\
\text { ano de } \\
\text { 2010/2011. }\end{array}$} & \multirow[b]{2}{*}{$\begin{array}{c}2007 \mathrm{a} \\
2011\end{array}$} & \begin{tabular}{|c} 
Correlaçã \\
o de \\
Spearman
\end{tabular} & Negativa* \\
\hline & & & $\begin{array}{c}\text { Regressão } \\
\text { de dados } \\
\text { em painel }\end{array}$ & Negativa* \\
\hline $\begin{array}{c}\text { Fazzini e } \\
\text { Dal Maso } \\
(2016)\end{array}$ & $\begin{array}{c}48 \\
\text { empresas } \\
\text { da Itália. }\end{array}$ & $\begin{array}{c}2008 \mathrm{a} \\
2013\end{array}$ & \begin{tabular}{|c|} 
Regressão \\
de dados \\
em painel \\
\end{tabular} & Positiva* \\
\hline $\begin{array}{l}\text { Santos } e t \\
\text { al. (2016) }\end{array}$ & $\begin{array}{c}18 \\
\text { empresas } \\
\text { brasileiras } \\
\text { listadas na } \\
\text { BM\&FBov } \\
\text { espa no } \\
\text { setor de } \\
\text { construção } \\
\text { civil. } \\
\end{array}$ & $\begin{array}{c}2010 \mathrm{a} \\
2014\end{array}$ & $\begin{array}{c}\text { Regressão } \\
\text { de dados } \\
\text { em painel }\end{array}$ & Positiva* \\
\hline \multirow{2}{*}{$\begin{array}{l}\text { Verbeeten } \\
\text { et al. } \\
(2016)\end{array}$} & \multirow{2}{*}{$\begin{array}{c}130 \\
\text { empresas } \\
\text { da } \\
\text { Alemanha. }\end{array}$} & \multirow{2}{*}{$\begin{array}{c}2006 \mathrm{a} \\
2009\end{array}$} & $\begin{array}{c}\text { Correlaçã } \\
\text { o de } \\
\text { Pearson }\end{array}$ & $\begin{array}{c}\text { Positiva } \\
\text { fraquíssim } \\
\mathrm{a}^{*}\end{array}$ \\
\hline & & & $\begin{array}{c}\text { Regressão } \\
\text { de dados } \\
\text { em painel }\end{array}$ & Negativa \\
\hline
\end{tabular}

Fonte: Elaboração própria.

Percebe-se por meio do Quadro 3 que os resultados encontrados nos estudos anteriores não permitem uma conclusão consistente em relação a associação do disclosure ambiental com o valor de mercado das empresas. Diante do exposto, o estudo busca contribuir com a literatura nacional, uma vez que analisa no contexto brasileiro a relevância no valor de mercado de empresas de alto impacto ambiental ao divulgar questões referentes ao meio ambiente utilizando metodologia diferenciada em relação aos estudos anteriores.

Nesta investigação utiliza-se a teoria dos jogos, que permite ranquear as empresas com base em seu disclosure ambiental comparando-o com o ranking de valor de mercado. Faz-se necessário, portanto, comparar empresas com as mesmas características, nesse caso, empresas de alto impacto ambiental em que se espera maior associação entre as variáveis estudadas. Ressaltase que nesta pesquisa o foco é avaliar o grau de associação e não a influência dos mesmos, justificando a utilização da presente metodologia.
Nacionalmente, verifica-se que as pesquisas que investigaram a associação entre disclosure ambiental e o valor de mercado utilizaram, até o presente momento, apenas a forma binária para mensurar o disclosure. Assim, a presente pesquisa busca inovar utilizando a forma de mensuração linear, assim como realizado por Rover (2013) quando investigada a relação entre o disclosure ambiental e o custo de capital próprio das empresas. Tal forma de mensuração é apropriada uma vez que permite verificar além da quantidade, a qualidade da informação evidenciada, conforme mencionado por Cormier, Magnam \& Val Velthoven (2005).

\section{Metodologia}

A pesquisa caracteriza-se como descritiva quanto ao objetivo, documental de acordo com os procedimentos e predominantemente quantitativa devido a abordagem do problema. A população do estudo é composta por 48 empresas da BM\&FBovespa, as quais são definidas como pertencentes aos setores de alto impacto ambiental segundo a lei $\mathrm{n}^{\mathrm{o}} 10.165$, de 27 de dezembro de 2000. Dentre as mesmas 4 delas foram excluídas da amostra por serem controladas por outras empresas da amostra, apresentando assim o mesmo Relatório de Sustentabilidade, 5 foram eliminadas da pesquisa por estarem em recuperação judicial durante o período analisado e, ainda, 15 foram excluídas por não apresentaram todas as informações necessárias para o cálculo do índice de disclosure ambiental e valor de mercado. Tais exclusões fizeram-se necessárias, pois a inclusão destas empresas na amostra poderia distorcer os achados da pesquisa. Logo, a amostra da pesquisa ficou composta por 24 empresas.

Para mensurar o nível de disclosure ambiental utilizou-se a métrica de Rover (2013), a qual foi adaptada para a pesquisa com o auxílio de uma pesquisadora qualitativa experiente na área contábil. Tal métrica é apresentada no Quadro 4.

Quadro 4. Métrica para a análise do disclosure ambiental
\begin{tabular}{|c|c|}
\hline CATEGORIAS & SUBCATEGORIAS \\
\hline \multirow{4}{*}{ Políticas } & $\begin{array}{c}\text { Declaração das políticas atuais / } \\
\text { Declaração das práticas ou ações } \\
\text { atuais }\end{array}$ \\
\cline { 2 - 2 } Ambientais & $\begin{array}{c}\text { Estabelecimento de metas / } \\
\text { Estabelecimento de objetivos } \\
\text { ambientais }\end{array}$ \\
\cline { 2 - 2 } & Certificação ambiental / Compliance \\
\hline
\end{tabular}

Revista de Negócios, v. 23, n. 2, p. 23-37, April, 2018. 


\begin{tabular}{|c|c|}
\hline & com leis e normas ambientais \\
\hline & $\begin{array}{l}\text { Parcerias, conselhos, fóruns } \\
\text { ambientais }\end{array}$ \\
\hline & $\begin{array}{c}\text { Prêmios ambientais / Participações em } \\
\text { índices ambientais }\end{array}$ \\
\hline & $\begin{array}{c}\text { Participação em organizações } \\
\text { ambientalistas }\end{array}$ \\
\hline & $\begin{array}{c}\text { Relacionamento ambiental com } \\
\text { stakeholders }\end{array}$ \\
\hline & Gestão de riscos ambientais \\
\hline & ISOs 14.000 \\
\hline Gestão e & Indicadores de desempenho ambiental \\
\hline $\begin{array}{l}\text { Auditoria } \\
\text { ambiental }\end{array}$ & $\begin{array}{c}\text { Revisão ambiental ou auditorias } \\
\text { ambientais }\end{array}$ \\
\hline & $\begin{array}{l}\text { Avaliação incluindo parecer } \\
\text { independente }\end{array}$ \\
\hline & Desperdícios / Resíduos \\
\hline & $\begin{array}{c}\text { Vazamentos / Derramamentos / Terra } \\
\text { utilizada }\end{array}$ \\
\hline Impactos & Reparos aos danos ambientais \\
\hline Ambientais & $\begin{array}{c}\text { Emissão de Gases do Efeito Estufa } \\
\text { (GEE) }\end{array}$ \\
\hline & $\begin{array}{c}\text { Emissão de substâncias destruidoras } \\
\text { da camada de ozônio }\end{array}$ \\
\hline & $\begin{array}{l}\text { Desenvolvimento de produtos } \\
\text { ecológicos }\end{array}$ \\
\hline Produtos & Reciclagem \\
\hline Ecológicos & $\begin{array}{l}\text { Processo de acondicionamento } \\
\text { (reutilização de embalagens) }\end{array}$ \\
\hline & Uso eficiente ou reutilização da água \\
\hline & $\begin{array}{l}\text { Desenvolvimento ou exploração de } \\
\text { novas fontes de energia }\end{array}$ \\
\hline Recursos & $\begin{array}{l}\text { Utilização de resíduos materiais para a } \\
\text { produção de energia }\end{array}$ \\
\hline Energéticos & $\begin{array}{c}\text { Consumo de energia proveniente de } \\
\text { fontes renováveis } \\
\end{array}$ \\
\hline & $\begin{array}{c}\text { Esforços da empresa para reduzir o } \\
\text { consumo de energia }\end{array}$ \\
\hline $\begin{array}{c}\text { Educação e } \\
\text { Pescuica }\end{array}$ & $\begin{array}{l}\text { Educação ambiental (internamente ou } \\
\text { comunidade) }\end{array}$ \\
\hline ambiental & $\begin{array}{l}\text { Apoio às pesquisas relacionadas ao } \\
\text { meio ambiente }\end{array}$ \\
\hline & $\begin{array}{c}\text { Projetos de Mecanismos de } \\
\text { Desenvolvimento Limpo (MDL) }\end{array}$ \\
\hline $\begin{array}{l}\text { Mercado de } \\
\text { Créditos de } \\
\text { Carbono }\end{array}$ & $\begin{array}{c}\text { Certificados de Emissões Reduzidas } \\
\text { (CER) }\end{array}$ \\
\hline & $\begin{array}{l}\text { Créditos de carbono ou compensações } \\
\text { de carbono }\end{array}$ \\
\hline & $\begin{array}{l}\text { Menção relativa ao desenvolvimento } \\
\text { sustentável }\end{array}$ \\
\hline $\begin{array}{l}\text { Sustentabilidade } \\
\text { e Biodiversidade }\end{array}$ & $\begin{array}{l}\text { Gerenciamento de florestas ou } \\
\text { reflorestamento }\end{array}$ \\
\hline & $\begin{array}{l}\text { Preservação da biodiversidade / } \\
\text { Preservação de recursos naturais } \\
\end{array}$ \\
\hline & Investimentos ambientais \\
\hline Informações & Receitas ambientais \\
\hline $\begin{array}{l}\text { Financeiras } \\
\text { Ambientais }\end{array}$ & $\begin{array}{c}\text { Custos ambientais / Despesas } \\
\text { ambientais }\end{array}$ \\
\hline & Passivos ou contingências ambientais \\
\hline
\end{tabular}

\begin{tabular}{|c|c|}
\hline \multirow{2}{*}{} & $\begin{array}{c}\text { Práticas contábeis de itens ambientais - } \\
\text { critérios de mensuração }\end{array}$ \\
\cline { 2 - 3 } & Seguro ambiental \\
\cline { 2 - 3 } & Ativos ambientais intangíveis \\
\hline
\end{tabular}

Fonte: Adaptado de Rover (2013).

Destaca-se que a métrica de Rover é composta por 40 subcategorias ambientais, para tanto houve a necessidade de adaptações, visto que, diferente da pesquisa de Rover (2013), este estudo não se preocupou com a quantidade de vezes que a informação foi divulgada, mas sim se a informação foi ou não evidenciada pela empresa.

Para mensurar cada uma das subcategorias ambientais adaptadas, optou-se em utilizar a ponderação linear. Tal quantificação atribui valores diferentes conforme a informação evidenciada, sendo que conforme Cormier et al. (2005), quanto maior a qualidade da informação, maior é o peso atribuído. A Tabela 1 traz em síntese os valores aplicados a cada tipo de informação.

Tabela 1. Critérios da ponderação linear

\begin{tabular}{c|c}
\hline CRITÉRIOS & LINEAR \\
\hline Não há divulgação & 0 \\
\hline Divulgações qualitativas & 1 \\
\hline Divulgações quantitativas não monetárias & 2 \\
\hline Divulgações quantitativas monetárias & 3 \\
\hline
\end{tabular}

Fonte: Adaptado de Rover (2013).

Por meio dos critérios apresentados na Tabela 1 buscou-se quantificar as subcategorias ambientais nos seguintes documentos: Demonstrações Financeiras Padronizadas (Balanço Patrimonial, Demonstração das Mutações do Patrimônio Líquido, Demonstração dos Fluxos de Caixa, Demonstração do Resultado do Exercício e Demonstração do Valor Adicionado), Notas Explicativas, Parecer do Auditor Independente, Parecer do Conselho Fiscal, Relatório do Comitê de Auditoria, Relatório de Sustentabilidade, Relatório Anual e Formulário de Referência (item 7.8). Tais documentos são os mesmos utilizados por Rover (2013) em sua pesquisa, com exceção do Relatório Anual e do item 7.8 do Formulário de Referência. Estes documentos foram inclusos na análise, uma vez que conforme as próprias empresas analisadas, os mesmos também podem evidenciar informações referentes a questões ambientais das empresas.

Cabe destacar ainda que para fazer a busca de tais informações, utilizou-se o auxílio do software NVivo, o qual realiza buscas por meio de palavras

Revista de Negócios, v. 23, n. 2, p. 23-37, April, 2018. 
semânticas. As palavras semânticas utilizadas são apresentadas no Quadro 5, as quais também foram escolhidas com o auxílio de uma pesquisadora qualitativa experiente da área contábil.

Quadro 5. Palavras semânticas utilizadas na análise de conteúdo

\begin{tabular}{|c|}
\hline PALAVRAS SEMÂNTICAS PARA INFORMAÇÕES \\
AMBIENTAIS \\
\hline Política; Prática; Ambiente; Ambiental; Meta; Objetivo; \\
Certificado; Compliance; Lei; Norma; Legislação; \\
Parceria; Conselho; Fórum; Prêmio; Índice; Fornecedor; \\
Cliente; Governo; Sociedade; Comunidade; Investidor; \\
Funcionário; Risco; 14000; 14.000; Desempenho; \\
Indicador; Auditoria; Revisão; Parecer independente; \\
Desperdício; Resíduo; Vazamento; Derramamento; Terra; \\
Danos; Reparos; Estufa; GGE; Ozônio; Ecológico; \\
Desenvolvimento de produtos; Reciclagem; Produtos \\
ecológicos; Reutilização; Embalagem; Reversa; Água; \\
Energia; Educação; Pesquisa; Mecanismos de \\
desenvolvimento limpo; MDL; Certificação; Certificado; \\
Carbono; CO2; Desenvolvimento sustentável; \\
Sustentabilidade; Floresta; Reflorestamento; Preservação; \\
Recursos naturais; Biodiversidade; Investimento; Receita; \\
Ganho; Custo; Despesa; Passivo; Contingência; Seguro; \\
Ativo; Intangível \\
\hline
\end{tabular}

Fonte: Elaboração própria.

Destaca-se que foi optado em utilizar a opção de busca do software NVivo que procura além das palavras semânticas, palavras semelhantes ou sinônimos das mesmas. Desta forma, após ser realizada a busca no software, foi lida cada parte selecionada pelo software e categorizadas as informações encontradas em cada uma das 24 empresas da amostra, nos anos de 2013 e 2014. Com efeito, foram estes os anos que antecederam a obrigatoriedade de divulgações ambientais. A inclusão de períodos posteriores inviabilizaria a aplicação da métrica de Rover (2013), pois esta foi desenvolvida anteriormente a obrigatoriedade das divulgações, sendo que itens que antes eram voluntariamente evidenciados tornaram-se obrigatórios após este período. Por fim, para chegar aos índices de disclosure ambientais foi dividida a quantidade de informações de cada subcategoria encontrada, pela quantidade máxima que a mesma poderia chegar, assim como realizado por Rover (2013).

Já para mensurar o valor de mercado das empresas foi multiplicado o preço da ação pela quantidade de ações de cada empresa no dia 31 de dezembro. Destaca-se que tais informações foram coletadas por meio da base de dados Economática®.
O período de 31 de dezembro foi escolhido, pois há a necessidade de se utilizar um momento no qual toda a informação evidenciada já foi absorvida pelo mercado. Logo, como o estudo utiliza relatórios não obrigatórios por lei, os quais não possuem um período específico para a evidenciação, optou-se em realizar a análise do valor de mercado no dia 31 e dezembro do ano posterior ao relatório.

Assim, para analisar a associação entre o nível de disclosure ambiental e o valor de mercado, foi utilizado o valor de mercado de 2014 em relação ao disclosure de 2013 e o valor de mercado de 2015 em relação ao disclosure de 2014. Isto, devido ao relatório ser divulgado apenas no ano posterior.

A técnica utilizada para ranquear as empresas conforme o nível de disclosure ambiental foi jogos escalares, enquanto o valor de mercado foi ranqueado de forma decrescente, conforme o valor encontrado pela variável. Por fim, salienta-se que a associação entre tais rankings foi verificada por meio do método de correlação de Kendall.

No que se refere as limitações da pesquisa destaca-se três aspectos: amostra, período de análise e conjunto de indicadores. Quanto a amostra, tem-se a exclusão de 24 empresas devido a falta de informação e o fato da não possibilidade de generalização dos resultados para outras empresas. O período se caracteriza como limitação pelo fato de utilizar-se de pesquisa qualitativa para mensurar o nível de disclosure ambiental das empresas e o período posterior ao analisado, devido a obrigatoriedade de divulgação ambiental que não é objetivo deste estudo. O conjunto de indicadores que mesmo com a utilização da métrica de Rover (2013) é subjetiva.

\section{Análise}

Neste capítulo são apresentados os resultados obtidos no estudo. Para tanto, foi necessário dividir este capítulo em três momentos. No primeiro apresentam-se os rankings dos anos de 2013 e 2014 das empresas da amostra conforme o nível de evidenciação ambiental. No segundo expõem-se os rankings de 2014 e 2015 das empresas da amostra conforme o valor de mercado. E no terceiro momento apresentam-se os achados da pesquisa quanto a associação do disclosure ambiental com o valor de mercado das empresas de alto impacto ambiental. 


\subsection{Empresas por Nível de Disclosure Ambiental}

Para a elaboração dos rankings das organizações da amostra conforme o nível de disclosure ambiental nos anos de 2013 e 2014, os Problemas de Programação Linear construídos foram o PPL-1 e o PPL-2, respectivamente.

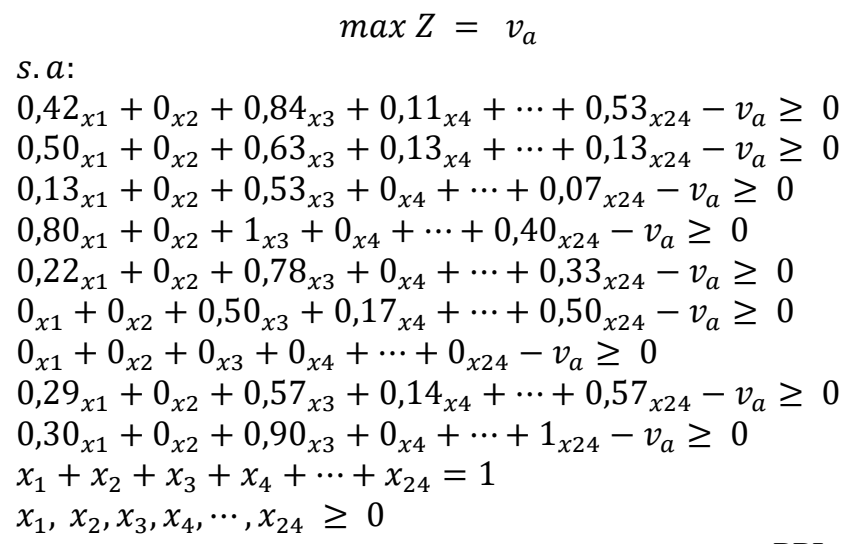

PPL-1

$$
\max Z=v_{a}
$$

s. $a$ :

$0,35_{x 1}+0_{x 2}+0,71_{x 3}+0,12_{x 4}+\cdots+0,47_{x 24}-v_{a} \geq 0$

$0,67_{x 1}+0_{x 2}+0,50_{x 3}+0,33_{x 4}+\cdots+0,17_{x 24}-v_{a} \geq 0$

$0,13_{x 1}+0_{x 2}+0,53_{x 3}+0_{x 4}+\cdots+0_{x 24}-v_{a} \geq 0$

$0,50_{x 1}+0_{x 2}+1_{x 3}+0_{x 4}+\cdots+0,33_{x 24}-v_{a} \geq 0$

$0,33_{x 1}+0_{x 2}+0_{x 3}+0_{x 4}+\cdots+0,17_{x 24}-v_{a} \geq 0$

$0_{x 1}+0_{x 2}+0,75_{x 3}+0,50_{x 4}+\cdots+0,25_{x 24}-v_{a} \geq 0$

$0_{x 1}+0_{x 2}+0_{x 3}+0_{x 4}+\cdots+0_{x 24}-v_{a} \geq 0$

$0,29_{x 1}+0_{x 2}+0,43_{x 3}+0,14_{x 4}+\cdots+0,43_{x 24}-v_{a} \geq 0$

$0,23_{x 1}+0_{x 2}+0,23_{x 3}+0,23_{x 4}+\cdots+0,77_{x 24}-v_{a} \geq 0$

$x_{1}+x_{2}+x_{3}+x_{4}+\cdots+x_{24}=1$

$x_{1}, x_{2}, x_{3}, x_{4}, \cdots, x_{24} \geq 0$

PPL-2

Nos PPLs supracitados as nove primeiras restrições referem-se as nove variáveis que formaram a categoria ambiental (Políticas ambientais; Gestão e auditoria ambiental; Impactos ambientais; Produtos ecológicos; Recursos energéticos; Educação e pesquisa ambiental; Mercado de créditos de carbono; Sustentabilidade e diversidade; Informações financeiras ambientais) e as demais restrições referem-se que a soma das estratégias não ultrapasse $100 \%$ e a não negatividade, respectivamente.

Mediante a resolução dos problemas de programação linear, verifica-se as estratégias ótimas de cada jogo. Os PPLs foram resolvidos por meio do software PLM 3.0. Depois de verificada a estratégia ótima sugerida: pura ou mista para o Jogador I na primeira rodada, a empresa (estratégia pura) ou as empresas (estratégia mista) que se apresentaram como estratégias ótimas foram retiradas do problema. De forma recorrente, o PPL foi sucessivamente executado até a formação completa do ranking.

$\mathrm{Na}$ Tabela 2 são expostos os rankings de 2013 e 2014, os quais foram elaborados por meio de tais PPLs.

Tabela 2. Rankings das empresas em relação ao nível de disclosure ambiental

\begin{tabular}{|c|c|c|c|c|}
\hline \multirow{2}{*}{ Pregão } & \multicolumn{2}{|c|}{ Resultado - 2013} & \multicolumn{2}{|c|}{ Resultado - 2014} \\
\hline & P. & Valor & P. & Valor \\
\hline Celul Irani & $1^{a}$ & $x_{16}=0,60$ & $2^{a}$ & $x_{16}=0,16$ \\
\hline Cosan & $2^{a}$ & $x_{3}=0,27$ & $9^{a}$ & $x_{3}=0,16$ \\
\hline Natura & $3^{a}$ & $x_{21}=0,08$ & $3^{a}$ & $x_{21}=0,35$ \\
\hline Vale & $4^{a}$ & $x_{15}=0,05$ & $7^{\mathrm{a}}$ & $x_{15}=0,45$ \\
\hline Ultrapar & $5^{a}$ & $x_{7}=0,68$ & $5^{a}$ & $x_{7}=0,24$ \\
\hline Braskem & $6^{a}$ & $x_{19}=0,22$ & $1^{\mathrm{a}}$ & $x_{19}=0,84$ \\
\hline Fibria & $7^{\mathrm{a}}$ & $x_{17}=0,09$ & $11^{\mathrm{a}}$ & $x_{17}=0,20$ \\
\hline Fer Heringer & $8^{a}$ & $x_{8}=0,01$ & $16^{\mathrm{a}}$ & $x_{8}=0,48$ \\
\hline Petrobras & $9^{a}$ & $x_{5}=0,72$ & $6^{\mathrm{a}}$ & $x_{5}=0,13$ \\
\hline Klabin & $10^{\mathrm{a}}$ & $x_{18}=0,28$ & $4^{\mathrm{a}}$ & $x_{18}=0,28$ \\
\hline Gerdau & $11^{\mathrm{a}}$ & $x_{24}=0,62$ & $8^{a}$ & $x_{24}=0,39$ \\
\hline Elekeiroz & $12^{\mathrm{a}}$ & $x_{20}=0,38$ & $13^{\mathrm{a}}$ & $x_{20}=0,54$ \\
\hline Paranapanema & $13^{\mathrm{a}}$ & $x_{1}=0,82$ & $14^{\mathrm{a}}$ & $x_{1}=0,46$ \\
\hline QgepPart & $14^{\mathrm{a}}$ & $x_{6}=0,18$ & $10^{\mathrm{a}}$ & $x_{6}=0,78$ \\
\hline Bradespar & $15^{\mathrm{a}}$ & $x_{14}=0,35$ & $18^{\mathrm{a}}$ & $x_{14}=0,46$ \\
\hline Raiadrogasil & $16^{\mathrm{a}}$ & $x_{13}=0,30$ & $21^{a}$ & - \\
\hline Petrorio & $17^{\mathrm{a}}$ & $x_{4}=0,23$ & $15^{\mathrm{a}}$ & $x_{4}=0,52$ \\
\hline Unipar & $18^{\mathrm{a}}$ & $x_{23}=0,13$ & $12^{\mathrm{a}}$ & $x_{23}=0,02$ \\
\hline Dimed & $19^{a}$ & $x_{11}=0,54$ & $17^{\mathrm{a}}$ & $x_{11}=0,54$ \\
\hline Vitalyze.Me & $20^{\mathrm{a}}$ & $x_{22}=0,46$ & $23^{a}$ & - \\
\hline Profarma & $21^{\mathrm{a}}$ & - & $19^{a}$ & - \\
\hline Br Pharma & $22^{a}$ & - & $20^{\mathrm{a}}$ & - \\
\hline Cremer & $23^{a}$ & - & $22^{a}$ & - \\
\hline Panatlantica & $24^{a}$ & - & $24^{\mathrm{a}}$ & - \\
\hline
\end{tabular}

- Estratégia.

Fonte: Dados da pesquisa.

$\mathrm{Na}$ Tabela 2, referente aos rankings das empresas frente o nível de disclosure ambiental, verifica-se que a empresa que ocupava a $1^{\mathrm{a}}$ posição no ranking de 2013 não se manteve na mesma posição no ranking de 2014. A empresa Celulose Irani, ocupante da $1^{\text {a }}$ posição do ranking no ano de 2013, diminuiu sua posição no ano posterior, passando a ocupar a $2^{\mathrm{a}}$ posição. Em contrapartida a empresa Braskem, a qual ocupava a $6^{\mathrm{a}}$ posição no

Revista de Negócios, v. 23, n. 2, p. 23-37, April, 2018. 
ano de 2013, aumentou sua posição no ano de 2014, passando a assumir o topo do ranking referente ao nível de disclosure ambiental.

Destaca-se ainda, que houve empresas que se mantiveram na mesma posição em ambos os períodos analisados. Dentre tais empresas verificou-se a Natura que se manteve em ambos os anos na $3^{\mathrm{a}}$ posição, assim como a Ultrapar que ocupou a $8^{\mathrm{a}}$ posição e a Panatlantica ocupante da $24^{\mathrm{a}}$ posição.

Dentre as empresas que menos evidenciaram questões ambientais nota-se que dentre as cinco empresas com piores colocações em 2013, quatro mantiveram-se nas cinco piores colocações no ano de 2014.

Salienta-se ainda que as empresas que se apresentaram nas primeiras posições dos rankings são organizações que divulgaram Relatórios Anuais ou de Sustentabilidade dos anos analisados. $\mathrm{E}$, diferentemente destas empresas, as organizações encontradas nas posições inferiores dos rankings ambientais são as quais não divulgaram tais relatórios.

Esses resultados evidenciam que a divulgação dos Relatórios Anuais ou de Sustentabilidade com maior qualidade de informação melhoram a posição das empresas. Nesse sentido, ressalta-se a necessidade de divulgação pontual abrangendo uma maior quantidade de subcategorias destacadas por Rover (2013) com o intuito de melhorar sua avaliação e, consequentemente, a competitividade no mercado.

\subsection{Empresas por Valor de Mercado}

Na Tabela 3 são evidenciados os resultados obtidos por meio da variável valor de mercado para cada uma das empresas da amostra, juntamente com a devida posição das mesmas frente a tal índice.

Tabela 3. Rankings das empresas em relação ao valor de mercado

\begin{tabular}{c|c|c|c|c}
\hline Pregão & $\begin{array}{c}\text { VM } \\
\mathbf{2 0 1} \\
\mathbf{3}\end{array}$ & $\begin{array}{c}\text { PA*Q } \\
(\mathbf{2 0 1 3 )}\end{array}$ & $\begin{array}{c}\text { VM } \\
\mathbf{2 0 1} \\
\mathbf{4}\end{array}$ & $\begin{array}{c}\text { PA*Q } \\
(\mathbf{2 0 1 4 )}\end{array}$ \\
\hline Petrobras & $1^{\mathrm{a}}$ & 125096726,2 & $1^{\mathrm{a}}$ & 111791339,3 \\
\hline Vale & $2^{\mathrm{a}}$ & 107134332,3 & $2^{\mathrm{a}}$ & 67148476,25 \\
\hline Br Pharma & $3^{\mathrm{a}}$ & 47015104,50 & $24^{\mathrm{a}}$ & 35941,95 \\
\hline Ultrapar & $4^{\mathrm{a}}$ & 27232293,97 & $4^{\mathrm{a}}$ & 32407997,40 \\
\hline Fibria & $5^{\mathrm{a}}$ & 16453877,25 & $5^{\mathrm{a}}$ & 28208714,11 \\
\hline
\end{tabular}

\begin{tabular}{c|c|r|c|r}
\hline Klabin & $6^{\mathrm{a}}$ & 14635202,58 & $3^{\mathrm{a}}$ & 38622897,04 \\
\hline Gerdau & $7^{\mathrm{a}}$ & 13182534,29 & $10^{\mathrm{a}}$ & 5869625,52 \\
\hline Natura & $8^{\mathrm{a}}$ & 12752406,87 & $8^{\mathrm{a}}$ & 10000601,71 \\
\hline Cosan & $9^{\mathrm{a}}$ & 10807194,45 & $9^{\mathrm{a}}$ & 9726141,32 \\
\hline Raiadrogasil & $10^{\mathrm{a}}$ & 8172109,41 & $7^{\mathrm{a}}$ & 11622076,63 \\
\hline Braskem & $11^{\mathrm{a}}$ & 7536652,72 & $6^{\mathrm{a}}$ & 11884634,68 \\
\hline Unipar & $12^{\mathrm{a}}$ & 3925304,75 & $17^{\mathrm{a}}$ & 455222,02 \\
\hline Bradespar & $13^{\mathrm{a}}$ & 3708486,79 & $11^{\mathrm{a}}$ & 1545270,96 \\
\hline QgepPart & $14^{\mathrm{a}}$ & 1756646,65 & $12^{\mathrm{a}}$ & 1452029,07 \\
\hline Dimed & $15^{\mathrm{a}}$ & 967370,40 & $13^{\mathrm{a}}$ & 1322110,00 \\
\hline Paranapanema & $16^{\mathrm{a}}$ & 754744,89 & $15^{\mathrm{a}}$ & 672242,41 \\
\hline Petrorio & $17^{\mathrm{a}}$ & 687178,80 & $14^{\mathrm{a}}$ & 807765,00 \\
\hline Celul Irani & $18^{\mathrm{a}}$ & 519192,78 & $16^{\mathrm{a}}$ & 494675,44 \\
\hline Profarma & $19^{\mathrm{a}}$ & 346729,67 & $19^{\mathrm{a}}$ & 195155,96 \\
\hline Cremer & $20^{\mathrm{a}}$ & 318643,14 & $18^{\mathrm{a}}$ & 412334,45 \\
\hline Panatlantica & $21^{\mathrm{a}}$ & 271546,53 & $20^{\mathrm{a}}$ & 187969,37 \\
\hline Fer Heringer & $22^{\mathrm{a}}$ & 255442,17 & $22^{\mathrm{a}}$ & 72706,95 \\
\hline Elekeiroz & $23^{\mathrm{a}}$ & 220395,00 & $21^{\mathrm{a}}$ & 173482,35 \\
\hline Vitalyze.Me & $24^{\mathrm{a}}$ & 64087,00 & $23^{\mathrm{a}}$ & 39181,56 \\
\hline Fon Dad
\end{tabular}

Fonte: Dados da pesquisa.

Frente as empresas que apresentaram os maiores índices de valor de mercado, conforme evidenciado pela Tabela 3, cabe-se destacar a Petrobras, a qual se apresenta na $1^{\mathrm{a}}$ posição em ambos os anos e a Vale, a qual encontra-se na $2^{\mathrm{a}}$, tanto no ranking referente ao ano de 2014 , como no ranking referente ao ano de 2015. Além destas, outras organizações Ultrapar $\left(4^{\mathrm{a}}\right)$, Fibria $\left(5^{\mathrm{a}}\right)$, Natura $\left(8^{\mathrm{a}}\right)$, Cosan $\left(9^{\mathrm{a}}\right)$, Fertilizantes Heringer $\left(22^{\mathrm{a}}\right)$ e Profarma $\left(19^{\mathrm{a}}\right)$ permaneceram ocupando as mesmas posições durante ambos os períodos.

Verifica-se ainda, por meio da Tabela 3, que dentre as cinco empresas que apresentaram os melhores índices de valor de mercado no ano de 2014, quatro mantiveram-se entre as cinco primeiras posições no ano de 2015. Já em relação as cinco empresas que apresentaram nas últimas posições no ano de 2014, foram também quatro a quantidade de empresas que permaneceram em tais posições no ano posterior.

4.3 Nível de disclosure ambiental e o valor de mercado

Em relação aos resultados encontrados por meio da associação entre os rankings de divulgação ambiental e os rankings de valor de mercado, verificados por meio da correlação de Kendall, os mesmos são expostos na Tabela 4.

Tabela 4. Correlação entre os rankings de divulgações ambientais e os de valor de mercado

\begin{tabular}{c|c|c}
\hline Período & $\begin{array}{c}\text { Correlação de } \\
\text { Kendall }\end{array}$ & Valores \\
\hline
\end{tabular}

Revista de Negócios, v. 23, n. 2, p. 23-37, April, 2018. 


\begin{tabular}{c|c|c}
\hline Disclosure Ambiental de & Coeficiente de & 0,319 \\
2013 - Valor & correlação & \\
\cline { 2 - 3 } de Mercado de 2014 & Sig. & 0,029 \\
\hline Disclosure Ambiental de \\
$\begin{array}{c}\text { 2014 - Valor } \\
\text { de Mercado de 2015 }\end{array}$ & $\begin{array}{c}\text { Coeficiente de } \\
\text { correlação }\end{array}$ & 0,471 \\
\cline { 2 - 3 } & Sig. & 0,001 \\
\hline
\end{tabular}

Fonte: Dados da pesquisa.

Conforme apresentado na Tabela 4, em ambos os períodos investigados houve uma associação positiva, moderada e significativa entre os rankings do nível de disclosure ambientais e os rankings de valor de mercado das empresas. Tais resultados indicam que as empresas com maiores níveis de evidenciação ambiental tendem a apresentar os maiores valores de mercado durante os períodos investigados.

Tais resultados corroboram com os achados de Iatridis (2013), em empresas da Malásia, Olayinka e Oluwamayowa (2014), em empresas cotadas na Nigéria, Fazzini \& Dal Maso (2016), em organizações italianas e com os achados de Santos et al. (2016), em empresas de construção civil brasileiras os quais utilizaram análise de dados em painel. Em contrapartida, os resultados encontrados não corroboram com as evidências de Sousa et al. (2014) no cenário brasileiro, uma vez que o autor encontrou uma associação inversa entre tais variáveis e também diverge dos achados de Verbeeten et al. (2016) em empresas alemãs que aplicaram correlação de Pearson e dados em painel.

Verifica-se ainda por meio da Tabela 4 um aumento no grau de associação do disclosure ambiental com o valor de mercado do primeiro para o segundo período analisado. Tal evidência sugere que houve um aumento na importância atribuída pelo mercado na divulgação de questões relacionadas com o meio ambiente por parte das empresas de alto impacto ambiental. Logo a qualificação da evidenciação deste tipo de informação pode refletir positivamente o valor de mercado das empresas, o que estimula uma melhoria em relação a tal divulgação em períodos posteriores por parte das empresas de alto impacto ambiental.

Cabe destacar que os resultados evidenciados na pesquisa convergem com a conclusão de Dye (1985) frente à Teoria do Disclosure Voluntário. Este fato decorre visto a evidência empírica que empresas com níveis de divulgações voluntárias ambientais mais elevadas tendem a apresentar valores de mercado superiores as suas concorrentes que divulgam menor quantidade de informações ambientais.

Além disto, os resultados do presente estudo corroboram com a vertente de pesquisa a qual afirma que uma maior divulgação voluntária aumenta a vantagem competitiva da empresa, visto que as empresas com maior transparência em relação a questões ambientais apresentaram melhores valores de mercado. Sendo assim, a percepção de Eccles et al. (2001), Konar e Cohen (2001), Kothari et al. (2009), Luca et al. (2012), Moreira et al. (2014) e Nekhiliet al. (2016) de que a divulgação de informações voluntárias tende a trazer benefícios para as organizações confirma-se neste estudo.

\section{Conclusão}

Para alcançar os objetivos deste estudo, realizou-se uma pesquisa descritiva, documental e predominantemente quantitativa. A população do estudo correspondeu as 48 empresas brasileiras pertencentes aos setores considerados de alto impacto ambiental, conforme a Lei $\mathrm{n}^{\circ} 10.165$, de 27 de dezembro de 2000, listadas na BM\&FBovespa. Porém, após terem sido realizadas exclusões necessárias, a amostra do estudo ficou composta por 24 organizações. Além disto, destaca-se que o período de análise que compreendeu os níveis de disclosure das empresas foram os anos de 2013 e 2014, enquanto que para a variável valor de mercado o período investigado foram os anos de 2014 e 2015, devido a necessidade de defasagem temporal.

Por meio dos modelos matemáticos, baseados em jogos escalares, verificou-se o posicionamento das empresas da amostra conforme o nível de disclosure ambiental. As organizações da amostra que ocuparam as melhores posições foram Celul Irani, Vale e Ultrapar. Em contrapartida, as organizações com os menores níveis de disclosure ambiental foram Panatlantica, Cremer, Dimed, Br Pharma e a Vitalyze.me.

Em relação aos rankings das organizações conforme o valor de mercado tem-se as empresas Petrobrás, Vale, Ultrapar e Fibria ocupantes das melhores colocações. Por outro lado, as empresas Vitalyze.me, Elekeiroz, Fer Heringer e a Panatlantica posicionaram-se nas colocações inferiores dos rankings.

As correlações dos os rankings ambientais com os rankings de valor de mercado das

Revista de Negócios, v. 23, n. 2, p. 23-37, April, 2018. 
organizações indicaram uma associação positiva e moderada entre o disclosure ambiental com o valor de mercado das empresas. Percebe-se por meio destes achados, que empresas que divulgam informações relacionadas com o ambiente no qual estão inseridas, a utilização de recursos naturais e a forma como buscam proteger o meio ambiente tendem a apresentar melhores valores no mercado de capitais frente as suas concorrentes que não divulgam tais informações.

Tais evidências corroboram com a conclusão de Dye (1985) em relação a Teoria do Disclosure Voluntário, e com a vertente de pesquisa que sugere que a divulgação de informações voluntárias por parte das empresas acarreta em benefícios para as mesmas, uma vez que os resultados empíricos desta pesquisa revelaram que empresas de alto impacto ambiental que divulgam informações voluntariamente tendem a apresentar melhores valores de mercado.

Por fim, cabe destacar os achados obtidos frente aos anos de análise. Comparando os dois períodos investigados, verificou-se um aumento no grau de associação do disclosure ambiental com o valor de mercado do ano de 2014 para o ano de 2015. Tal resultado corrobora com o indicado na literatura de que o mercado está cada vez mais exigente quanto a divulgação por parte das empresas de informações referentes as questões que envolvem o meio ambiente.

\section{Implicações e Futuras Pesquisas}

Por meio da presente pesquisa, percebe-se a relevância das empresas pertencentes aos setores de alto impacto ambiental divulgarem informações que envolvam o ambiente no qual estão inseridas, a utilização de recursos naturais e a forma como buscam proteger o meio ambiente, visto as evidencias de uma associação moderada entre o disclosure ambiental e o valor de mercado destas empresas. Diante disso, recomenda-se para as organizações de alto impacto ambiental; que buscam melhorar seus valores de mercado; divulgarem as subcategorias ambientais de Rover (2013), visto que a maior divulgação das mesmas está associada com um maior valor de mercado de tais empresas.

Quanto às recomendações para futuras pesquisas destaca-se aplicar o constructo desta pesquisa em organizações pertencentes aos setores de médio e baixo impacto ambiental. Desta forma tornando possível verificar a existência de peculiaridades entre empresas de setores com impacto ambientais distintos.

Além disto, como recomendação sugere-se expandir o período de análise, buscando assim verificar se realmente houve um aumento constante no grau de associação dos disclosure ambiental com o valor de mercado das empresas nos anos atuais. Tal evidência contribuiria com os achados desta pesquisa de que houve um aumento na relevância dada pelos investidores nos últimos anos frente a evidenciação de questões ambientais por parte das empresas.

\section{Referências}

Abrahamson, M., \& Ridder, A. de. (2015). Allocation of shares to foreign and domestic investors: Firm and ownership characteristics in Swedish IPOs. Research in International Business and Finance, 34, 52-65.

Adina, P., \& Ion, P. (2008). Aspects Regarding Corporate Mandatory and Voluntary Disclosure.Annals of the University of Oradea: Economic Science, 3(1), 1407-1411.

Bauer, M., \& Naime, R. (2012). Estado da arte da evidenciação social e ambiental voluntária. REUNIR: Revista de Administração, Contabilidade e Sustentabilidade, 2(2), p. 39-60.

Chaves, E. de P. E S., \& Pimenta Júnior, T. (2013). Relação entre Valor de Mercado e Ativo Intangível na Bovespa. Revista de Administração IMED, 3(3), 239-251.

Cormier, D., Magnan, M., \& Van Velthoven, B. (2005). Environmental disclosure quality in large German companies: economic incentives, public pressures or institutional conditions? European Accounting Review, 14(1), 3-39.

Cruz, C. V. O. A., \& Lima, G. A. S. F. de. (2010). Reputação corporativa e nível de disclosure das empresas de capital aberto no Brasil. Revista Universo Contábil, 6(1), 85-101.

Dye, R. A. (2001). An evaluation of "essays on disclosure" and the disclosure literature in accounting. Journal of Accounting and Economics, 32(1), 181-235.

Revista de Negócios, v. 23, n. 2, p. 23-37, April, 2018. 
Dye, R. A. (1985). Disclosure of nonproprietary information. Journal of accountingresearch, 123145.

Fernandes, C. M. G. M., Costa, P. De S., \& Câmara, A. R. G. S. da. (2007). Análise da relação entre volume de investimentos em sistemas de informação divulgados e valor de mercado das empresas brasileiras de capital aberto do setor de energia elétrica. Revista Universo Contábil, 3(1),27-37.

Freguete, L. M., Nossa, V., \& Funchal, B. (2015). Responsabilidade Social Corporativa e Desempenho Financeiro das Empresas Brasileiras na Crise de 2008/Corporate Social ResponsibilityandBrazilianFirms' Financial Performance. Revista de Administração Contemporânea, 19(2), 232-248.

Furuta, F., \& Santos, A. dos (2010). Comitê de auditoria versus conselho fiscal adaptado: a visão dos analistas de mercado e dos executivos das empresas que possuem ADRs. Revista Contabilidade \& Finanças, 21(53), 1-23.

Gibbins, M., Richardson, A., \& Waterhouse, J. (1990). The management of corporate financial disclosure: opportunism, ritualism, policies and process. Journal of Accounting Research, 28(1), 121-143.

Iatridis, G. E. (2013). Environmental disclosure quality: Evidence on environmental performance, corporate governance and value relevance. Emerging Markets Review, 14, 55-75.

Levitt, A. (1998). The importance of high quality accounting standards.Accounting Horizons, 12(1), 79-82.

Lian, Y., Su, Z., \& Gu, Y. (2011). Evaluating the effects of equity incentives using PSM: Evidence from China. Frontiers of Business Research in China, 5(2), 266-290.

Lins, L. dos S., \& Silva, R. N. S. (2009). Responsabilidade Sócio-Ambiental ou Greenwash: uma avaliação com base nos relatórios de sustentabilidade ambiental. Sociedade, Contabilidade e Gestão, 4(1), 91-105.
Lopes, A. C., Luca, M. M. M. De, Góis, A. D., \& Vasconcelos, A. C. de. (2015). Disclosure Socioambiental, Reputação Corporativa e Criação de Valor nas Empresas Listadas na BM\&FBovespa. Anais do Congresso USP de Controladoria e Contabilidade. São Paulo, SP, Brasil.

Morais, M. R. P. B. de. (2014). Corporate social responsibility levels and firm performance: Evidence from countries in crisis(Dissertação demestrado).Faculdade de Economia, Universidade Nova de Lisboa, Lisboa, Portugal.

Murcia, F. D. (2009). Fatores Determinantes do Nivel de Disclosure Voluntário de Companhias Abertas no Brasil (Tese de doutorado). Faculdade de Economia, Administração e Contabilidade, Universidade de São Paulo, São Paulo, SP, Brasil.

Murcia, F. D., Souza, F. C. de, Dill, R. P., \& Costa Junior, N. A. (2010). Impacto do nível de disclosure corporativo na volatilidade das ações de companhias abertas no Brasil. Anais do Congresso USP de Controladoria e Contabilidade. São Paulo, SP, Brasil.

Nascimento, A. R. do, Santos, A. dos, Salotti, B., \& Múrcia, F. D. (2009). Disclosure social e ambiental: análise das pesquisas científicas veiculadas em periódicos de língua inglesa. Contabilidade Vista \& Revista, 20(1), 15-40.

Neiva, R. A. (1999). Valor de mercado da empresa: modelos de avaliação econômicofinanceira de empresas exemplos de avaliação com cálculos. Atlas.

Oliveira, M. C., Gomes, C. A. S., \& Costa, D. M. (2004). Uma análise do conteúdo e da forma das instituições de natureza sócio-econômica e ambiental divulgadas através das demonstrações contábeis: o caso das empresas baianas. Anais do Encontro Nacional de Pesquisa em Administração - EnANPAD. Curitiba, PR, Brasil.

Olayinka, A. O., \& Oluwamayowa, I. O. (2014).Corporate environmental disclosures and market value of quoted companies in Nigeria. The Business \& Management Review, 5(3), 171-184. 
Pardo, A., \& Torro, H. (2007). Trading with asymmetric volatility spillovers. Journal of Business Finance \& Accounting, 34(9-10), 15481568.

Rover, S. (2013). Disclosure socioambiental $e$ custo de capital próprio de companhias abertas no Brasil(Tese de doutorado). Faculdade de Economia, Administração e Contabilidade, Universidade de São Paulo, São Paulo, SP, Brasil.

Rover, S., \& Santos, A. dos. (2014). Revisitando os Determinantes do Disclosure Voluntário Socioambiental no Brasil: Em Busca de Robustez na Mensuração da Variável Socioambiental. Contabilometria, 1(2), 15-35.

Salotti, B. M., \& Yamamoto, M. M. (2005). Ensaio sobre a teoria da divulgação. Brazilian Business Review, 2(1), 53-70.

Santos, L. M. da S., \& Araújo, R. A. de M., Leite Filho, P. A. M. (2016). Divulgação Voluntária e o Valor de Mercado: Um Estudo nas Empresas Brasileiras de Construção Civil Listadas na BM\&Fbovespa. Anais do Congresso Anpcont. Ribeirão Preto, SP, Brasil.

Sobhani, F. A., Amran, A., \&Zainuddin, Y. (2009). Revisiting the practices of corporate social and environmental disclosure in Bangladesh. Corporate Social Responsibilityand Environmental Management, 16(3), 167-183.

Sousa, C. B. de, Silva, A. F. da; Ribeiro, M. de S., \& Weffort, E. F. J. (2014). Valor de mercado e disclosure voluntário: estudo empírico em companhias listadas na BM\&FBOVESPA. Revista Ambiente Contábil, 6(2), 94-115.

Tian, Y., \& Chen, J. (2009). Concept of voluntary information disclosure and a review of relevant studies.International Journal of Economics and Finance, 1(2), 55-59.

Verbeeten, F. H. M.,Gamerschlag, R.,\&Möller, K. (2016). Are CSR disclosures relevant for investors? Empirical evidence from Germany. Management Decision, 54(6), 1359-1382.

Verrecchia, R. E. Discretionary disclosure. (1983). Journal of accounting and economics, 5, 179-194.
Verrecchia, R. Essays on disclosure.(2001). Journal of Accounting and Economics, 32(1), 97180.

Qiu, Y., Shaukat, A., \& Tharyan, R. (2014). Environmental and social disclosures: Link with corporate financial performance. The British Accounting Review, 30, 1-15.

Weil, D. (2002). The benefits and costs of transparency: A model of disclosure based regulation. Social Science Research Network.

Zanoello, C. F., Manfroi, L., Palma, D. L., \& Zeni, E. (2015). Relação entre Disclosure Voluntário e os Indicadores Econômicos e Financeiros: Um Estudo Aplicado em Empresas Listadas na BM\&FBovespa. Tecnológica, 2(1), 427-447.

Revista de Negócios, v. 23, n. 2, p. 23-37, April, 2018. 